\title{
ASSESSMENT OF HYPOXEMIA USING DOWNES SCORE IN NEONATES WITH RESPIRATORY DISTRESS
}

Sabina Shrestha, ${ }^{1}$ Sujit Kumar Shrestha, ${ }^{1}$ Gentle Sunder Shrestha, ${ }^{2}$ Madhu Sudhan Dhakal ${ }^{1}$

${ }^{1}$ Department of Pediatrics, Nepal Medical College and Teaching Hospital, Attarkhel, Gokarneswor-8, ${ }^{2}$ Department of Anesthesia, Tribhuwan University Teaching Hospital, Maharajgunj, Kathmandu, Nepal

\begin{abstract}
Respiratory distress in newborn is a common problem leading to hypoxemia. Pulse oximetry is the tool for measuring oxygen saturation noninvasively and blood gas analysis is the gold standard for oxygen monitoring. Downes score can be used as an alternative to assess respiratory distress clinically and determine the need of oxygen supplementation when these facilities are not available. This study was done to evaluate the validity of Downes score to assess hypoxemia in newborn with respiratory distress. This is a cross sectional descriptive study conducted from June 2020 to February 2021 in Neonatal Intensive Care Unit of Nepal Medical College Teaching Hospital. Oxygen saturation of newborn with respiratory distress was measured by pulse oximetry. At the same time the neonate was assessed for respiratory distress clinically using Downes score. Downes score and oxygen saturation measured by pulse oximetry were compared. Hypoxemia was defined as oxygen saturation less than $90 \%$ in term/ post term newborn and less than $88 \%$ in preterm baby. Similarly, neonate was considered to be hypoxic when Downes score was $\geq 5$. The accuracy of Downes score was assessed by its sensitivity and specificity in detecting hypoxemia. Altogether 121 neonates were included in the study. Sensitivity and specificity of Downes score of 5 was $94.12 \%$ and $93.10 \%$ respectively. In conclusion, Downes score can be used as a clinical diagnostic means for assessing hypoxemia in neonates with respiratory distress
\end{abstract}

\section{KEYWORDS}

Downes score, hypoxemia, newborn, respiratory distress

Received on: April 6, 2021

Accepted for publication: August 8, 2021

\section{CORRESPONDING AUTHOR}

Dr. Sabina Shrestha,

Associate Professor,

Department of Pediatrics,

Nepal Medical College and Teaching Hospital, Attarkhel, Gokarneshwor-8, Kathmandu, Nepal

Email: sabinajoshi1234@hotmail.com

Orcid No: https://orcid.org/0000-0003-4652-7492

DOI: https://doi.org/10.3126/nmcj.v23i3.40375 


\section{INTRODUCTION}

Respiratory disorders are the most frequent cause of admission in neonatal intensive care unit in both term and preterm infants. Signs of respiratory distress are the indication for physical examination and diagnostic evaluation including determination of ventilation by arterial blood gases and oxygenation by pulse oximetry. ${ }^{1}$ Pulse oximetry is the primary tool for noninvasive oxygen monitoring in neonates. Pulse oximeter provides continuous measurement of hemoglobin oxygen saturation with high level of accuracy. ${ }^{2}$ In a study, Hay found oxygen saturatio $\left(\mathrm{SpO}_{2}\right)$ measured by pulse oximeter was highly correlated with arterial blood oxygen saturation $(r=0.99) .^{3}$ Pulse oximetry can give inaccurate result in the conditions like inappropriate sensor placement, presence of high intensity light (phototherapy devices), fetal hemoglobin values $>50 \%$ and presence of carboxyhemoglobin or methemoglobin. $^{2}$ Low peripheral perfusion and motion artifact are the two most common causes of inaccurate $\mathrm{SpO}_{2}$ reading. ${ }^{4}$ Arterial oxygen tension $\left(\mathrm{PaO}_{2}\right)$, measured under steady state conditions from an indwelling catheter, is the gold standard for oxygen monitoring. ${ }^{2}$ However these facilities may not be available everywhere in our country.

Respiratory distress when prolonged and unattendedleadstohypoxemia,hypercarbiaand acidosis leading to pulmonary vasoconstriction and persistence of fetal circulation, thereby aggravating hypoxemia, worsening prognosis. ${ }^{5}$ Therefore, a clinical evaluation to determine the presence of hypoxemia at early stage without supporting tools is very important. The severity of respiratory distress clinically can be assessed by Silverman- Anderson Score and Downes Score. While the Silverman Anderson Retraction Score is more suited for pretrems, Downes Score is more comprehensive and can be applied to any gestational age and condition. ${ }^{6}$ Downes score can be used as a clinical diagnostic means for assessing hypoxia in clinical respiratory distressed neonates. ${ }^{7}$ This study was done to determine the validity of Downes score for assessing hypoxemia in neonates with respiratory distress.

\section{MATERIALS AND METHODS}

This is a cross sectional descriptive study conducted from June 2020 to February 2021 in Neonatal Intensive Care Unit (NICU) of Nepal Medical College Teaching Hospital, Attarkhel, Kathmandu, Nepal. Sample size was calculated using the formula $n=z^{2} p(100-p) / d^{2}$ with expected prevalence of respiratory distress of $28 \%$ and the margin of error, $d$ of $8 \%$. All the term, post term and preterm newborns with respiratory distress who fulfilled the inclusion criteria were included in the study. The Informed consent was taken from all the parents. The newborn was considered to have respiratory distress when there is presence of at least two of the following criteria: respiratory rate of more than 60 per minute in quiet and resting baby, chest retraction and grunting. ${ }^{8}$

Detail maternal and neonatal history was taken. Complete physical examination of all the newborn including head to toe examination was done. Gestational age was assessed using Modified Ballard Score. All the newborn were evaluated with pulse oximetery and Downes score at the same time. Hypoxemia was considered if $\mathrm{SpO}_{2}$ is $<90 \%$ in full term and $<88 \%$ in pre term babies. ${ }^{7}$ Based on Downes score new born has clinical respiratory distress when the score is $>4$ and $>7$ indicate impending respiratory failure. Presence of hypoxemia was considered when the score was $\geq 5 .{ }^{9}$ Oxygen saturation was measured by pulse oximeter by placing it on the right or left foot for 30 seconds, when it detected a good pulse and the value on the monitor did not changed for 10 second. Babies were managed according to the severity of the illness and outcome was observed. Data of the patient was collected in a preformed Proforma and analyzed using SPSS 16 software. Ethical clearance was obtained from Nepal Medical College Institutional Review Committee.

\section{RESULTS}

There were 121 neonates included in the study. The characteristic of the subjects are shown

\begin{tabular}{lcc}
\multicolumn{3}{l}{ Table 1: Demographic Characteristics of } \\
neonates
\end{tabular}


Table 2. Prediction of hypoxemia using cutoff point from Downes score

\begin{tabular}{lcc} 
Downes Score & Sensitivity & Specificity \\
$\geq 1$ & $100.0 \%$ & $0.0 \%$ \\
$\geq 2$ & $100.0 \%$ & $4.6 \%$ \\
$\geq 3$ & $100.0 \%$ & $33.3 \%$ \\
$\geq 4$ & $100.0 \%$ & $55.2 \%$ \\
$\geq 5$ & $94.1 \%$ & $93.1 \%$ \\
$\geq 6$ & $44.1 \%$ & $97.7 \%$ \\
$\geq 7$ & $29.4 \%$ & $100.0 \%$ \\
$\geq 8$ & $20.6 \%$ & $77.7 \%$ \\
\hline
\end{tabular}

Table 3: Sensitivity and Specificity of Downes score parameter to assess hypoxemia

Parameter Sensitivity Specificity

$\begin{array}{lcc}\text { Respiratory rate } & 100.0 \% & 45.0 \% \\ \text { Cynosis } & 41.0 \% & 86.0 \% \\ \text { Retraction } & 97.0 \% & 10.0 \% \\ \text { Grunting } & 97.0 \% & 54.0 \% \\ \text { Air entry } & 11.0 \% & 100.0 \%\end{array}$

in Table 1. Out of 121 newborn 34 (28.1\%) were hypoxic detected by pulse oximetry. Cut off point of hypoxemia determined by Receiver Operator Curve (ROC) curve was at Downes score of 5. Area under the ROC curve was 0.96 which is highly significant (Fig. 1). Sensitivity and specificity of Downes Score of 5 in detecting hypoxia is $94.1 \%$ and $93.1 \%$ respectively. Prediction of hyoxemia using comparative cut off point from Downes Score is shown in Table-2. On analyzing the different parameters of Downes score, sensitivity of respiratory rate in detecting hypoxemia was $100 \%$ and specificity was $45 \%$ respectively (Table-3). Outcome of the newborn was poor when Downes score is 7 or more (Table-4).

\section{DISCUSSION}

During the study period neonatal admission due to respiratory distress in NICU was $26.0 \%$ whereas the incidence was $34.3 \%$ in the previous study done in the same institute with most common cause being meconium aspiration syndrome (21.1\%). ${ }^{10}$ Similar study showed $34.0 \%$ cases admitted in NICU with respiratory distress where the most common

\begin{tabular}{|c|c|c|c|c|c|c|c|c|c|}
\hline \multirow{2}{*}{ Outcome } & \multicolumn{8}{|c|}{ Downe Score } & \multirow{2}{*}{ Total } \\
\hline & 1 & 2 & 3 & 4 & 5 & 6 & 7 & 8 & \\
\hline Improved & 4 & 23 & 16 & 33 & 21 & 5 & 1 & 4 & 107 \\
\hline Expired & & & & & & & 2 & 3 & 5 \\
\hline DOR & & 2 & 3 & 2 & & & & & 7 \\
\hline LAMA & & & & & & 2 & & & 2 \\
\hline Total & 4 & 25 & 19 & 35 & 21 & 7 & 3 & 7 & 121 \\
\hline
\end{tabular}

DOR: discharged on request; LAMA: Left against medical advice

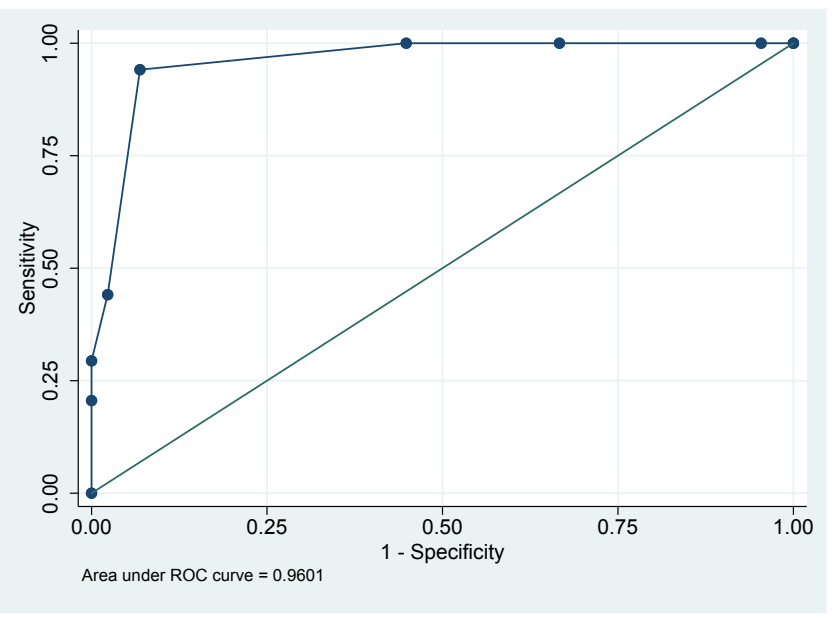

Fig. 1. ROC Curve cause was transient tachypnea of newborn ( 44.0\%). ${ }^{11}$ Incidence of hypoxemia in our study was $28.1 \%$ which is slightly lower compared to another study where the incidence is $36 \%{ }^{7}$

Our study showed the sensitivity and specificity of Downes score with cut off value at 5 as $94.1 \%$ and $93.1 \%$ respectively which is similar to another study where the sensitivity was $88 \%$ and the specificity was $81 \% .^{7}$ One of the study showed parameters like birth weight, gestational age, APGAR score, oxygen saturation, and Downes score could be used together to predict mortality and requirement of respiratory support in the resource limited setting. ${ }^{12}$

Evaluation of individual clinical signs of 
respiratory distress in neonatal hypoxemia showed different results. Duke et $a l^{13}$ found that cyanosis had good sensitivity and specificity. Retraction and grunting has less sensitivity. In another study, on analysis of each Downes score parameter; respiratory rate, chest retraction and air entry possessed high sensitivity with low specificity, where as cyanosis and grunting resulted in low sensitivity with high specificity. ${ }^{7}$ Our study had mixed result with respiratory rate, grunting and chest retraction had high sensitivity and low specificity where as cyanosis and air entry has low sensitivity and high specificity.

Outcome of our study showed all the newborns who expired had Downes score of 7 or more. Similar result was seen in another study where all the deaths (100\%) in term babies due to respiratory distress was significantly associated with Downes score of $>7 .{ }^{14}$ Downes score of $>6$, extreme low birth weight, preterm delivery and cesarean delivery were found to be the independent risk factors for infant death. ${ }^{15}$
Downes score $>6$ at 15-20 minutes of starting continuous positive airway pressure (CPAP) in sepsis and pneumonia were associated with CPAP failure and was also an independent predictors of outcome. Downes score can be used at periphery to monitor response and to decide about referral in absence of sophisticated test. ${ }^{16}$

In conclusion Downes score can be used to assess hypoxemia in newborn with respiratory distress with $94.1 \%$ sensitivity and $93.1 \%$ specificity.

\section{ACKNOWLEDGEMENT}

We would like to thank Dr. Vinutha Silvanus, Associate Professor and Head of Department of Community Medicine of Nepal Medical College for helping in data analysis.

Conflict of interest: None

Source of research fund: None

\section{REFERENCES}

1. Shawn K, Ahlfeld. Respiratory tract disorder. Nelson Text Book of Pediatrics (21 thed). Philadelphia: Elsevier 2020: 929-49.

2. James A, Adams. Blood gas and pulmonary function monitoring. Mannual of neonatal care ( $7^{\text {th }}$ ed). Philadelphia: Lippincott Williams \& Wilkins 2012: 393-6.

3. Hay WW, Brockway J, Eyzaguirre. Neonatal pulse oximetry: accuracy and reliability. Pediatrics 1989; 83: 717-22.

4. Salyer JW. Neonatal and pediatric pulse oxmetry. Respir Care 2003; 48: 386-96.

5. Sai SKM, Siva Sankara MYV, Yarakeswara RP, Madhusudhan K, Pundareekaksha V, Pathrudu GB. Approach to respiratory distress in the newborn. Int'l $J$ Health Res Mod Integrated Med Sci 2015; 2: 24-35.

6. Mathai SS, Raju U, Kanitkar M. Management of respiratory distress in the newborn. Med J Armed Forces India 2007; 63: 269-72. Doi:10.1016/S03771237(07)80152-3.

7. Rusmawati A, Haksari EL, Naning R. Downes score as a clinical assessment for hypoxia in neonates with respiratory distress. Paediatr Indonesiana 2008; 48: 342-5.

8. Singh M. Care of the newborn. $5^{\text {th }}$ ed. New Delhi: Publications; 2002: 4.

9. Downes JJ, Vidyasagar D, Morrow GM, Boggs Sagar TR. Respiratory distress syndrome of newborn infant. Clin Pediatr 1970; 9: 325-31.
10. Rijal P, Shrestha M. Senario of neonatal respiratory distress in tertiary hospital. J Nepal Health Res Counc 2018; 16: 131-5.

11. Barkiya SM, Venugopal N, Kumari V. Clinical -etiological profile and outcome of neonatal respiratory distress. Int'l J Sci Study 2016; 3: 18992. DOI:10.17354/ijss/2016/82.

12. John BM, Venkateshwar V, Dagar V. Predictor of outcome in neonates with respiratory distress. J Nepal Paediatr Soc 2015; 35: 31-7. doi:http:// dx.doi.org/10.3126/jnps.v35i1.11868

13. Duke T, Blaschke AJ, Sialis S, Bonkowsky JL. Hypoxaemia in acute respiratory and in non respiratory illnesses in neonates and children. Arch Dis Child 2002; 86: 108-12.

14. Brahmaiah P, Reddy KR. Etiological study of respiratory distress in newborn. Int'l J Contemp Med Res 2017; 4: 2202-6.

15. Luo J, Yu J M , Chen J, Li Q, Feng Z. Prevalence and predictors of infant mortality of respiratory distress syndrome in Beijing and Jiangxi Provinces of PR China. A retrospective cohort analysis. Iran Red Crescent Med J 2019; 21: e90679. doi:10.5812/ircmj.90679.

16. Buch P, Makwana AM, Chudasama RK. Usefulness of Downes score as clinical assessment tool and bubble CPAP as primary respiratory support in neonatal respiratory distress syndrome. $J$ Pediatr Sci 2013; 5: e176. 